
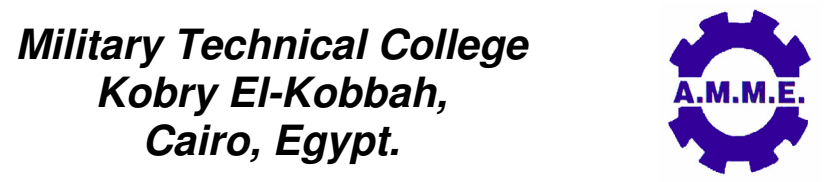
$15^{\text {th }}$ International Conference on Applied Mechanics and Mechanical Engineering.

\title{
Al/Mg METAL MATRIX COMPOSITE FOR MICRO LAMINATED/NANO PARTICULATE INTERPHASE
}

\author{
B. M. Rabeeh ${ }^{1}$ and Y. Fouad ${ }^{2}$
}

\begin{abstract}
Hot Isostatic Pressing, HIPing, of 6082 Al-alloy and AZ31 magnesium alloy is applied in Al-Mg foil-foil technique symmetrical arranged. However, delamination is a major limitation of lamellar composite structure, an emerging methodology introduced with micro laminated and/or delocalized nano particulate interphase. Mitigation of crack as well as toughening mechanisms is an objective. Parametric study (temperature, pressure and holding time) established for the control of interface/interphase kinetics. HIPing parameters as well as alloying elements have a dominant effect on kinetic of formation interphase. Lamellar metal matrix composites introduced with new micro laminated composite interphase. Micro-plasticity induced the formation of metal flow along with interfacial bonding as well as, low melting depressant (LMD) Zn. LMD induced the localized interphase structure enriched with either Al or Mg. Alloying element segregation tends to form nano composite structure or micro laminated composite in a solid state processing. Parametric study has been prompted to redesign lamellar structure for the control of interphase and interface with no delamination and porosity. Microstructural characterization, mechanical characterization is also established via optical microscopy scanning electron microscopy, energy dispersive Xray spectroscopy and tensile testing. Chemical and mechanical bonding via inter diffusion processing with LMD are dominant for interphase kinetics. Mechanical characterization with interfacial shear strength is also introduced with hardness testing. HIPing processing is successfully applied on 6082 Al-alloy and AZ31 magnesium alloy for both particulate composite or micro-laminated composite processing. The interphase kinetic established through localized micro plasticity, metal flow, LMD and delocalized Al oxide and Mg oxide. The morphology of interphase is cached with interesting structures that need more studies.
\end{abstract}

\section{KEY WORDS}

HIPing, Hybrid, Composite, micro-laminated, particulate, interface and interphase.

1 Professor, Dept. of Eng. and Materials Science, German Univ. in Cairo, Egypt.

2 Assistant Professor, Dept. of Eng. and Materials Science, German Univ. in Cairo, Egypt. 


\section{INTRODUCTION}

Mg alloy along with Aluminum alloy is being introduced for a lamellar composite structure processing that recommended for many applications. Mg alloys are being increasingly employed in the aerospace, automobile and $3 \mathrm{C}$ (Computer, Communication, Consumer electricsproducts) industries as important structural materials because of their low density, high strength-to-weight ratio, good damping characteristics and low casting costs, etc.[1]. One of the major drawbacks of magnesium alloys in many applications is their low corrosion resistance $[2,3]$ reported that introducing an outer ply of aluminum alloy could improve the corrosion resistance of the magnesium substrate effectively, while maintaining the low density and high specific strength of the assembly. Al/Mg/Al foils are symmetrically hot isostatic pressed, HIPed at different parametric study. Temperature, pressure as well as holding time are being controlled and studied for lamellar metal matrix composite processing. The Al/Mg-based laminated composites can be comprised to meet a wide variety of demands. Temperature ranges are selected from $450^{\circ} \mathrm{C}$ to $560^{\circ} \mathrm{C}$ for different holding times 10, 20 and 30 minutes in a working chamber of hydraulic press of 30 ten capacity. However, the bonding processes mentioned above require special facilities, such as vacuum system, complex equipment or high-cost instrument, etc. The present work introduced with new emerged facility that induce metal flow, air bleeding as well as diffusion processing [4-10]. The kinetic of interphase is also introduced with scanning electron microscopy along with energy dispersive X-ray spectroscopy and mechanical characterization. Hot Isostatic Pressing is now being applied to fabricate $\mathrm{Al}(6082) / \mathrm{Mg}-3 \mathrm{Al}-1 \mathrm{Zn}$ (AZ31) laminated composites as an emerging method for bonding of dissimilar materials in a solid state processing. In particular, Bakr et al. demonstrated the feasibility to produce a lamellar MMC with controlled interphase/interface by HIPing method [12]. However, delamination is its limitation. Besides, few data have been reported on the bonding conditions and the assembly of multiple plates during HIPing. Toughening mechanisms are introduced along interphase by delocalized nano particulate of ceramic phase (Alumina and magnesia). The kinetic of ceramic phase that hinder dislocations and slipping induce crack mitigation and toughening mechanisms. The fabrications of Al 6082-AZ31-Al 6082intermetallic laminated composites combining using Hipping techniques and their influence on the microstructures, phase constitutions, the joining interfaces of composites and the bonding strength and tensile strength of the fabricated laminated composite are introduced.

\section{EXPERIMENTAL PROCEDURES}

The extrinsically modified $\mathrm{Al} / \mathrm{Mg}$ alloys are introduced via HIPing at different parametric study. Chemical compositions of the intrinsically alloyed monolithic materials; Al 6082 and Mg Az31 are presented in Table 1.

Table 1. Chemical Composition of Al 6082 and AZ31 Magnesium Alloy.

\begin{tabular}{|c|c|c|c|c|c|c|c|c|}
\hline Alloys & $\mathrm{Cu}$ & $\mathrm{Zn}$ & $\mathrm{Mn}$ & $\mathrm{Si}$ & $\mathrm{Mg}$ & $\mathrm{Cr}$ & $\mathrm{Fe}$ & $\mathrm{Al}$ \\
\hline $\mathrm{Al} 6082$ & 0.04 & 0.02 & 0.05 & 1.92 & 0.79 & 0.15 & 0.24 & $\mathrm{Bal}$. \\
\hline & & & & & & $\mathrm{Ca}$ & $\mathrm{Ni}$ & $\mathrm{Al}$ \\
\hline $\mathrm{AZ31}$ & $<0.05$ & 1.05 & 0.20 & $<0.15$ & Bal. & $<0.04$ & $<0.005$ & 3.10 \\
\hline
\end{tabular}


$\mathrm{Al}$ and $\mathrm{Mg}$ alloy are prepared as thin foil/sheet of $3 \mathrm{~mm}$ thickness and different dimensions of $100 \times 50 \mathrm{~mm}$ (lengths $\mathrm{x}$ width). A hydraulic press with hot working chamber is applied with special fixture that promotes metal flow and diffusion kinetics. Al/Mg foil/foil technique symmetrically HIPed at different parametric study of temperature $450^{\circ} \mathrm{C}$ to $560^{\circ} \mathrm{C}$, and press of 30 Ten, with holding time varied from 10 , 20, to 30 minutes. Different HIPed samples are tested for microstructural observation to investigate bonding characteristics, interphase kinetics as well as delamination behavior. Scanning electron microscopy and energy dispersive X-ray spectroscopy is applied for microstructural characterization and chemical analysis. The best results of parametric study are applied for tensile test samples. Mechanical characterization is applied for both composite and its constituents. Al alloy, Mg alloy as well as $\mathrm{Al} / \mathrm{Mg}$ metal matrix composite (MMC) samples are separately tested using servo hydraulic tensile testing machine.

\section{RESULTS AND DISCUSSION}

Interfacial bonding of laminated composite materials is an interesting point of study. $\mathrm{Al} / \mathrm{Mg} / \mathrm{Al}$ lamellar structure is introduced by Hot Isostatic Pressing, HIPing, in three plies for structural applications. A new emerging processing of solid state processing is introduced to study the kinetic of interphase/interface under HIPing conditions. Temperature, pressure and holding time are controlled with microstructural analysis and EDX to introduce interfacial behavior and mechanical characterization. The kinetic of interphase in a lamellar composite structure introduces in steps of formulation with microstructural observations along with alloying elements effect that induce either micro-laminated structure or delocalized particulates that induce toughening mechanisms. However, delamination is a major limitation in a lamellar composite structure; this work introduces a mitigation behavior of delamination along with new introduced toughening mechanisms along interphase/interface.

Compared with other bonding methods, the bonding strength of the experimental laminates prepared by hipping bonding was medium due to delamination. For diffusion bonding, the maximum bonding strength of pure $\mathrm{Al} /$ pure $\mathrm{Mg}$ laminate with or without interlayer was $86.1 \mathrm{MPa}$ [4] and $22.7 \mathrm{MPa}$ [6], respectively; and that of $2024 \mathrm{Al}$ alloy/AZ31B Mg alloy and $6061 \mathrm{Al}$ alloy/AZ31BMg alloy was $56 \mathrm{MPa}[8]$ and 41.3 MPa [4], respectively. The maximum bonding strength of $7075 \mathrm{Al}$ alloy/AZ31B $\mathrm{Mg}$ alloy fabricated by explosive welding was $70 \mathrm{MPa}$ [10]. The maximum bonding strength of Al 6082/AZ31/ Al 6082 laminated composite fabricated by hipping in this work was $95.4 \mathrm{MPa}$. The bonding strength depends on the thermomechanical processing conditions of the laminated composite. Mechanical bonding occurs instantaneously or over a very short time period and depends on the forces of attraction between the atoms. It is believed that the not only mechanical bond played a major role in the bonding strength in this research but also kinetic of interphase/interface. As roll bonding started at a HIPing temperature, elemental concentration gradients played a role in driving certain elements from the internal layers to the interfaces. Metal flow, along with micro-laminated interface is induced by diffusion mechanism. In addition to new delocalized interphase flow from interface with aluminum oxide, alumina, and magnesium oxide, magnesia particulate/whiskers that induces toughening mechanisms with crack mitigation. 


\section{Microstructural Analysis}

During HIPing, A/Mg/Al 3-ply introduced at different parametric study of temperature, pressure and holding time. Aluminum ply reveal more ductility compared with $\mathrm{Mg}$ ply that induced transverse micro cracking along interface in Mg ply and presented in Figure 1. Figure 1: Al/Mg metal matrix composite with clear bonded interface and micro transverse cracking. This sample is HIPed at $530^{\circ} \mathrm{C}$ for 30 minutes and high press 30Ten. Figure 2 presents $\mathrm{Al} / \mathrm{Mg} \mathrm{MMC}$ with lateral micro cracking, that HIPed at $560^{\circ} \mathrm{C}$ for 20 minutes and high press 30Ten. The increase in HIPing temperature induces delocalized melting of $\mathrm{Mg}$ with lateral cracking. Figure 3 presents $\mathrm{Al} / \mathrm{Mg}$ metal matrix composite with clear bonding interface at $530^{\circ} \mathrm{C}$ for 30 minutes and high press 20Ten. The control of metal flow along with air bleeding at 20 minute with 20 Ten press introduces a clear interfacial bonding along $\mathrm{Al} / \mathrm{Mg}$ interface. The interface growth induces a clear interphase with delocalized zone of interests in a sample HIPed at $550^{\circ} \mathrm{C}$ for 20 minutes and high press 20Ten. However, the growth kinetic, delamination with lateral cracking along interface more dominant that presented in Figure 4. Figure 5 presents $\mathrm{Al} / \mathrm{Mg}$ metal matrix composite with clear bonding interface but with minor transverse cracking $540^{\circ} \mathrm{C}$ for 20 minutes and high press 15Ten. The reduction of press to 10 ten loading induce clear bonding interface with micro-laminated in aluminum and clear metal flow (Figure 6). Figure 6 presents $\mathrm{Al} / \mathrm{Mg}$ metal matrix composite with micro laminated interphase and bulk flow interface at $540^{\circ} \mathrm{C}$ for 20 minutes and high press $10 \mathrm{Ten}$. Slight increase in temperature and pressure at the same holding time induces interfacial growth. Figure 7 introduces $\mathrm{Al} / \mathrm{Mg}$ metal matrix composite with micro laminated interphase, bulk interfacial growth and material flow interphase at $550^{\circ} \mathrm{C}$ for 20 minutes and high press 15Ten. New interphase kinetics introduces at Figure 8micro laminated interphase and delocalized Nano particulate/whiskers interphase at $550^{\circ} \mathrm{C}$ for 20 minutes and high press 10Ten. High magnification of the interphase established with delocalized whiskers enriched with alumina as well as magnesia in bulk aluminum enriched interphase (Figure 9).

\section{Energy Dispersive X-Ray Spectroscopy EDX}

Energy dispersive X-ray spectroscopy EDX is applied on sample (Figure 9) to study micro constituents of composite. Fig. 10 presents elemental distributions across Al 6082/AZ31/AI 6082 interface of the laminated composite: (a) bulk Mg ply(left), interphase (middle), and bulk Al ply(right). The diffusion characteristics of aluminum through interface and magnesium induce delocalized interphase with magnesium oxide and aluminum oxide.

\section{Mechanical Testing}

Mechanical characterization established for both micro-constituents and bulk composite at different conditions. Stress-strain diagram applied for both Al-6082 and Mg-AZ31ply separately and presented in Fig. 11. Figure 12 presents typical stressstrain diagram of the Al 6082/AZ31/Al 6082 laminated composite that HIPed at $540^{\circ} \mathrm{C}$ for 20 minutes and high press 10 Ten. The modification established at interphase induces stress-strain diagram that presented in Figure 13. Nonlinear stress-strain diagram (Fig. 13) reveal hardening exponent and minor delamination established at sample HIPed at $550^{\circ} \mathrm{C}$ for 20 minutes and high press 10 Ten. Crack 
mitigation, toughening mechanisms and more ductility established for the new sample that presented in Figure 9.

\section{CONCLUSIONS}

$\mathrm{Al} / \mathrm{Mg} / \mathrm{Al}$ lamellar structure is established by Hot Isostatic Pressing, HIPing, in three plies for structural applications. Parametric study with a new emerging processing of solid state processing is introduced to study the kinetic of interphase/interface under HIPing conditions. Temperature, pressure and holding time are controlled with microstructural analysis and EDX to study interfacial behavior and mechanical characterization. The kinetic of interphase in a lamellar composite structure is introduced in steps in microstructural evidence along with alloying elements segregation.

Either micro-laminated structure or delocalized particulates are established with new toughening mechanisms along interface. Delamination of interface along with crack mitigation introduced with an increase of both strength and ductility in stress-strain diagram. The application of $\mathrm{Al} / \mathrm{Mg} \mathrm{MMC}$ established at $550^{\circ} \mathrm{C}$ for 20 minutes and high press 10Ten. The enhancement of interfacial shear stress established with nonlinear stress-strain diagram induced more toughening behavior.

\section{REFERENCES}

[1] Hidetoshi Somekawa, Hiroyuki Watanabe, ToshijiMukai, Kenji Higashi, "Low temperature diffusion bonding in a superplastic", Scripta Materialia, 48 (2003) 1249-1254.

[2] Zhang XP, Zhao ZP, Wu FM, et al. "Corrosion and wear resistance of AZ91D magnesium alloy with and without micro arc oxidation coating in Hank's solution", J Mater Sci. 2007;42:8523-8.

[3] Zhao LM, Zhang ZD. "Effect of Zn alloy interlayer on interface microstructure and strength of diffusion-bonded Mg-Al joints", Scripta Mater 2008; 58:283-6.

[4] Li YJ, Liu P, Wang J, et al. "XRD and SEM analysis near the diffusion bonding interface of Mg/Al dissimilar materials Vacuum", 2008;82:15-9.

[5] Liu FC, Liang W, Li XR, "Improvement of corrosion resistance of pure magnesium via vacuum pack treatment", J Alloys Comp. 2008; 461:399-403.

[6] Liu LM, Tan JH, Zhao LM, et al. "The relationship between microstructure and properties of Mg/Al brazed joints using Zn filler metal", Mater Charact. 2008; 59: 479-83.

[7] Mahendran G, Balasubramanian V, Senthilvelan T. "Developing diffusion bonding windows for joining AZ31B magnesium-AA2024 aluminum alloys", Mater Des 2009;30:1240-4.

[8] Liu XB, Chen RS, Han EH. "Preliminary investigations on the $\mathrm{Mg}-\mathrm{Al}-\mathrm{Zn} / \mathrm{Al}$ laminated composite fabricated by equal channel angular extrusion", J Mater Process Technol 2009; 209:4675-81.

[9] Del Valle, J.A., Pérez-Prado, M.T., Ruano, O.A., 2005. Accumulative roll bonding of a Mg-based AZ61 alloy. Mater. Sci. Eng. A 410-411, 353-357. 
[10] Yan YB, Zhang ZW, Shen W, et al. "Microstructure and properties of magnesium AZ31B-aluminum 7075 explosively welded composite plate", Mater Sci. Eng A 2010; 527:2241-5.

[11] Wu K, Chang H, Maawad E, et al. "Microstructure and mechanical properties of the Mg/Al laminated composite fabricated by accumulative roll bonding ARB" Mater Sci. Eng A 2010;527:3073-8.

[12] Bakr M. RABEEH, Mona M. EL BATANOUNY, Ali E. EL ASHRAM "Microstructural Characterization And Solid State Processing Of Cu-Zn-Al Shape Memory Alloy In A Metal Matrix Composite" Canadian Journal on Mechanical Sciences and Engineering Vol. 2, No. 2 February 2011, pp. 11-17.

\section{Figures}

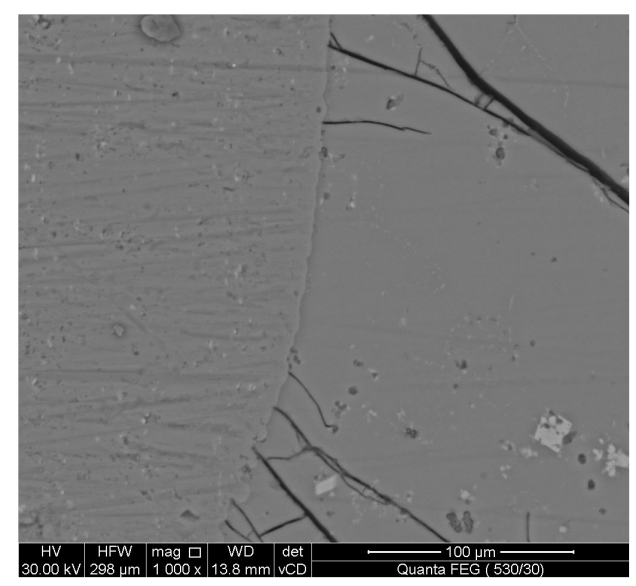

Figure 1: $\mathrm{Al} / \mathrm{Mg}$ metal matrix composite with interface micro cracking at $530^{\circ} \mathrm{C}$ for 30 minutes and high press 30Ten.

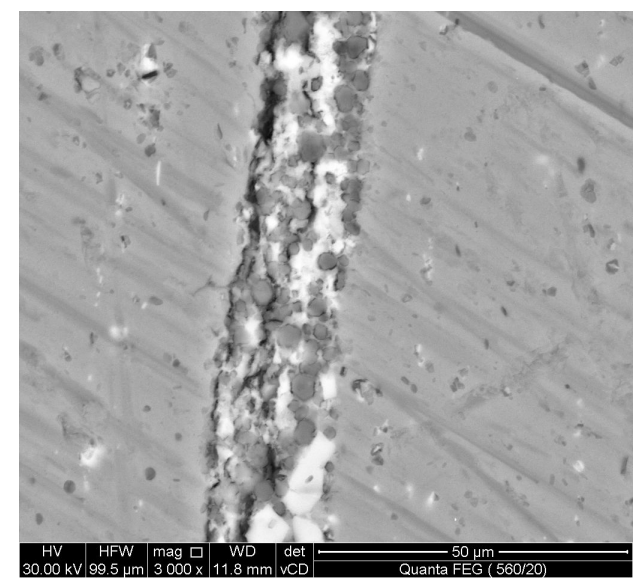

Figure 2: Al/Mg metal matrix composite with interface lateral cracking at $560^{\circ} \mathrm{C}$ for 20 minutes and high press 30Ten. 


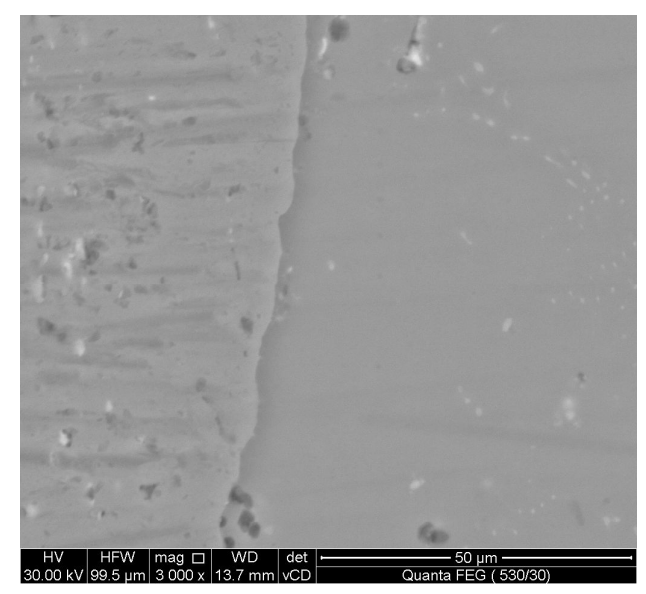

Figure 3: $\mathrm{Al} / \mathrm{Mg}$ metal matrix composite with clear bonding interface at $530^{\circ} \mathrm{C}$ for 30 minutes and high press 20Ten.

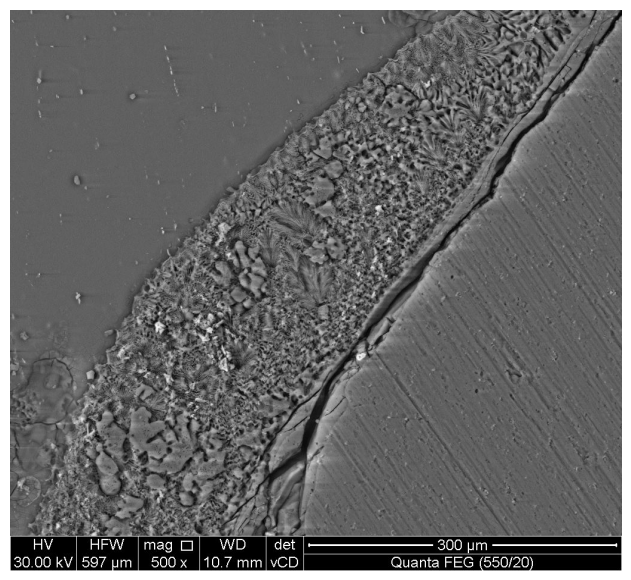

Figure 4: $\mathrm{Al} / \mathrm{Mg}$ metal matrix composite with delocalize interphase and lateral cracking at $550^{\circ} \mathrm{C}$ for 20 minutes and high press 20 Ten.

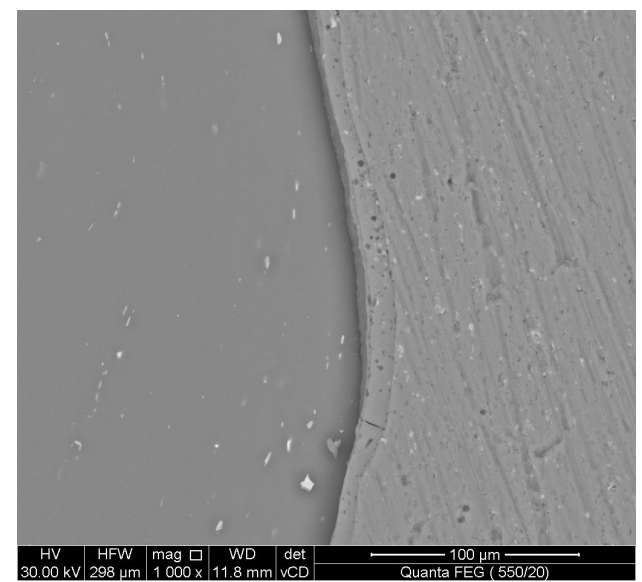

Figure 5: Al/Mg metal matrix composite with clear bonding interface with minor transverse cracking $540^{\circ} \mathrm{C}$ for 20 minutes and high press 15 Ten. [Low mag.]. 


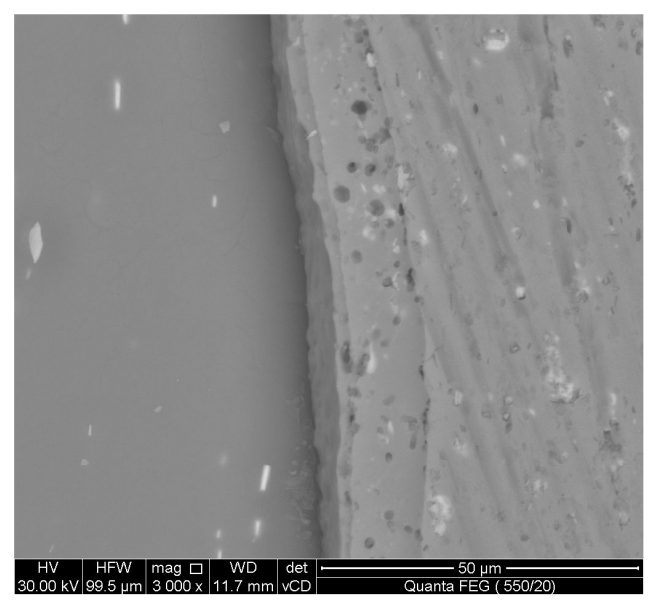

Figure 6: $\mathrm{Al} / \mathrm{Mg}$ metal matrix composite with micro laminated interphase and bulk flow interface at $540^{\circ} \mathrm{C}$ for 20 minutes and high press 10 Ten. [High mag.]

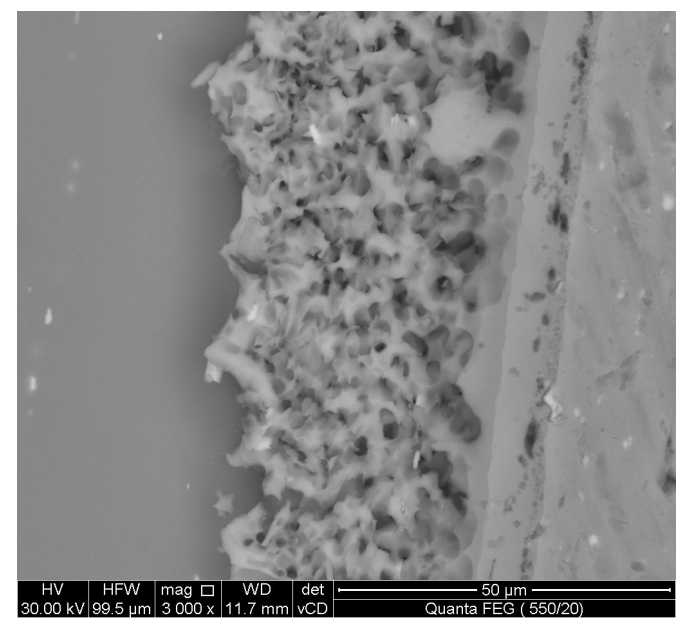

Figure 7: Al/Mg metal matrix composite with micro laminated interphase and bulk material flow interphase at $550^{\circ} \mathrm{C}$ for 20 minutes and high press 15Ten. [High mag.]

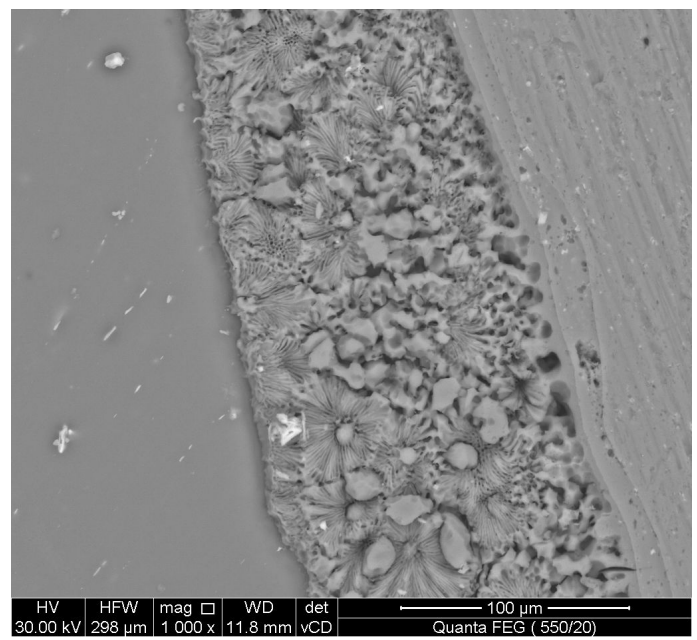

Figure 8: Al/Mg metal matrix composite with micro laminated interphase and delocalized Nano particulate/whiskers interphase at $550^{\circ} \mathrm{C}$ for 20 minutes and high press 10Ten. 


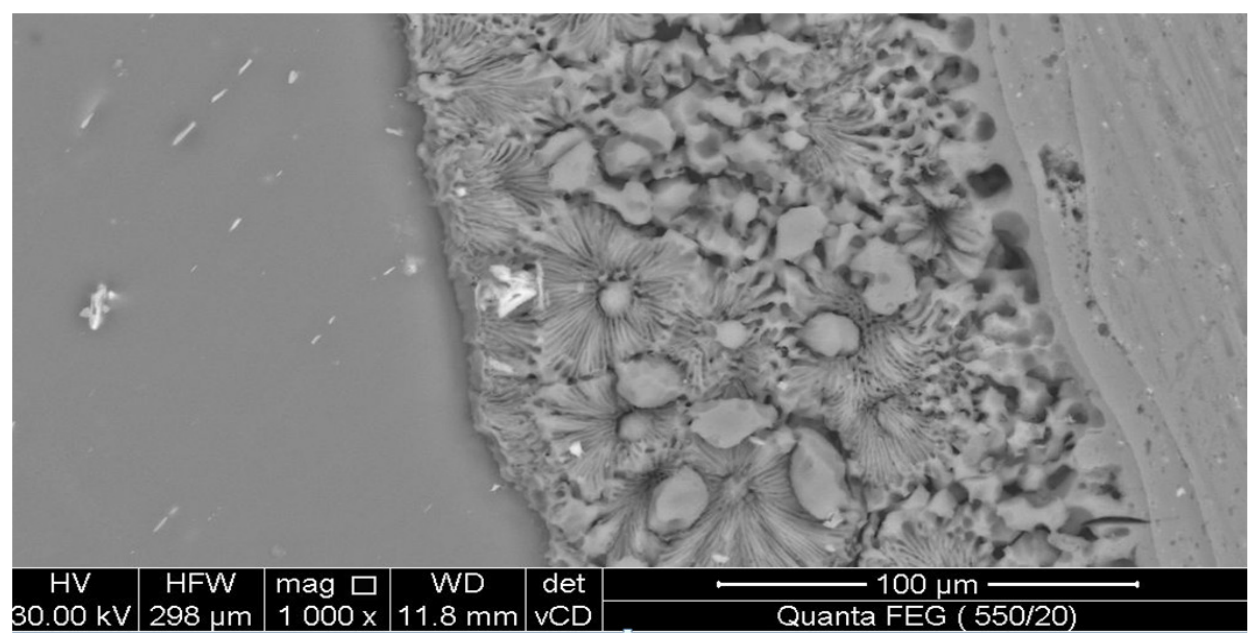

Figure 9: Al/Mg metal matrix composite with micro laminated interphase and delocalized Nano particulate/whiskers interphase at $550^{\circ} \mathrm{C}$ for 20 minutes and high press 10Ten. [High Mag.]
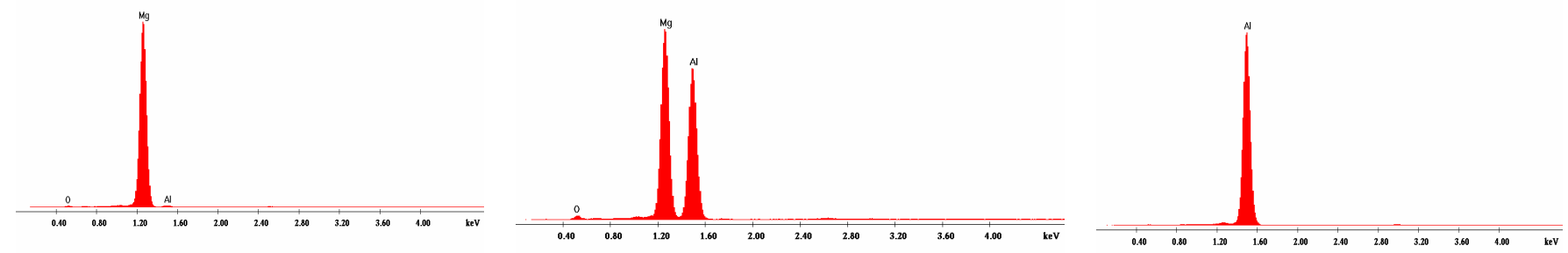

Fig. 10: Elemental distributions across Al 6082/AZ31/AI 6082 interface of the laminated composite: (a) bulk Mg ply(left), interphase (middle), and bulk Al ply(right).
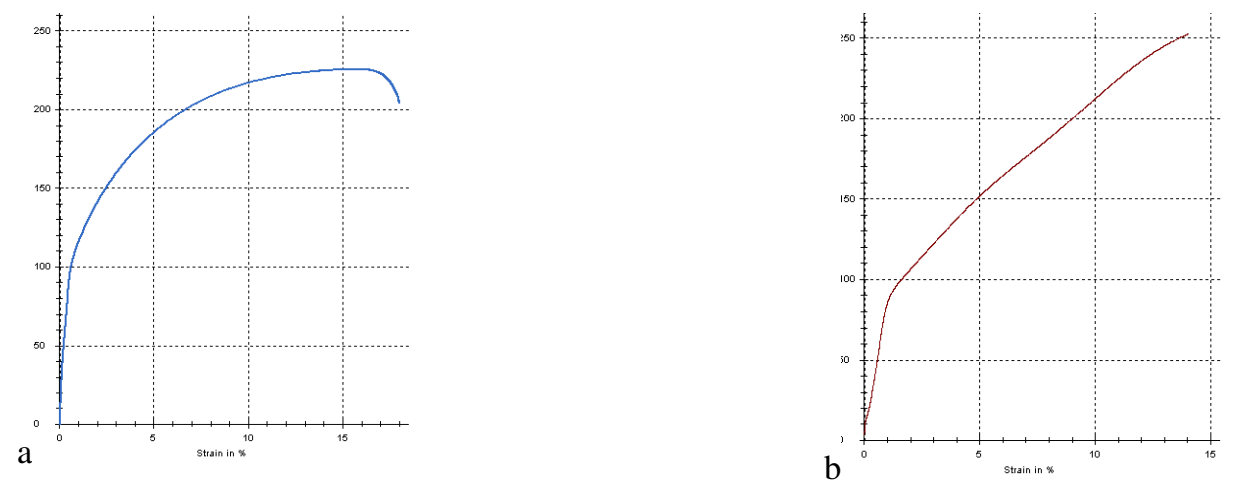

Fig. 11: Typical stress-strain curve of (a) Al 6082 (b) AZ31 before hipping. 


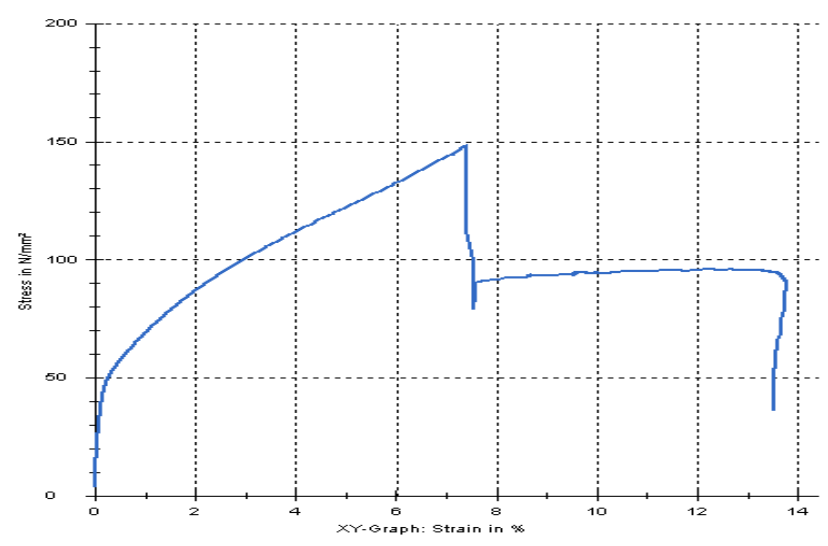

Fig.12: Typical stress-strain curve of the Al 6082/AZ31/Al 6082 laminated composite after the shear strength test.

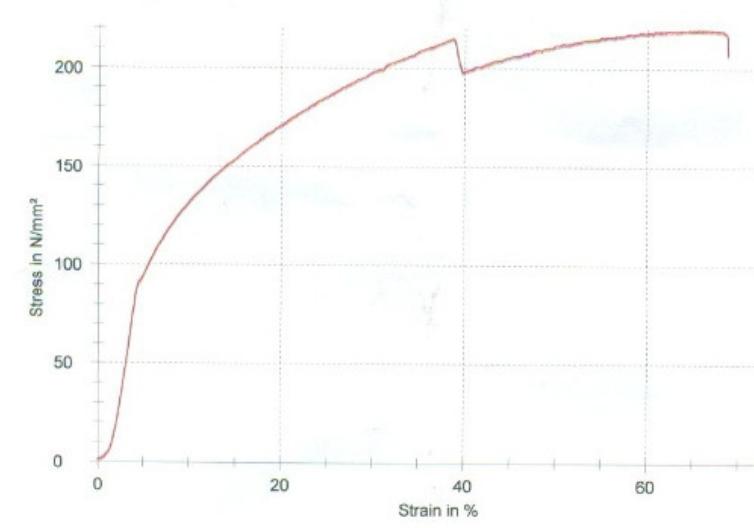

Fig.13: Typical stress-strain curve of the Al /Mg/Al laminated composite after the modified interphase. 